\title{
Degree of fit: University students in paid employment, service delivery and technology
}

\author{
Marilyn J. Anderson \\ James Cook University
}

\begin{abstract}
This study examines the ease of, and proficiency in, accessing web based technology, and the convenience (or otherwise) of service delivery in the facilitation of combining study with paid work for undergraduate students of James Cook University (JCU), Cairns Campus, Far North Queensland. Considering that the typical new millennium student is enrolled full time and works 18 hours per week, when $40 \%$ of the sample $(n=148)$ believes that, overall, the university does not cater well to students in paid employment, alarms must sound. These are consumers who work to study, then study to improve their work prospects, and they comprise approximately $50 \%$ of the Cairns Campus student population (2,625, from May 2005 census). Further, about one quarter of the students surveyed admit to barely coping with the technological requirements of being a university student 9 weeks into a 13week semester. The conclusions here are serious, that JCU (at the very least) requires more effective means and media to cater for the needs of a growing number of students, both part time and full time, in paid employment. Ways to improve the degree of fit between the academy and working students, between students and technology, and between delivery of services and student uptake are suggested.
\end{abstract}

\section{Introduction}

Taking up paid employment, whether part time or full time, clearly influences university students' engagement with their study load, even if that, too, is part time or full time. The often precarious balance in negotiating a successful path through tertiary study, at whatever age or stage of entry, is mediated by imperatives to stay fiscally afloat or, for some, to build a credible work history toward a career or, for others, to gain work experience. For yet others, the often fraught juggle of child or dependant care with study and employment can be an overwhelming burden, the dropout rate yawning to swallow up the ill-prepared. Whatever the pressures, to obtain and retain paid employment while studying at university is becoming the norm and the stereotypical terms 
'traditional university student' and 'non-traditional university student' are in metamorphosis.

A range of influences abound (parental or spousal economic support, part time versus full time study load, choice of degree, 'juggle-ability' of work and study commitments, age or stage of entry, child care commitments) but useful foci for this current study are the ease of, and proficiency in, accessing web based technology, and the convenience (or otherwise) of service delivery in the facilitation of combining study with work for students of JCU, Cairns Campus. How does timetabling and delivery of lectures and tutorials match the needs of students more and more likely to be also in paid work? How does access to, and use of, technology aid, or detract from, the juggling of real life responsibilities with successful scholarship? Indeed, how can any university, not just JCU, enhance its response to the changing needs and nature of a growing body of its consumers? What are the degrees of fit between the academy and students, between students and technology, between delivery of services and student uptake, between being a university student and being employed?

Over the last ten years, becoming a university scholar has been influenced by significant forces other than learning. Students, especially those new to the task, face greater emphases on self funding and technological competency now more than ever before. McInnis (2001, cited in Vickers, Lamb \& Hinkley, 2003, p.18) calculates that "on average, the number of hours that university students spend in paid employment has increased by 38 per cent over the past 10 years." Just as changes to Austudy and the Higher Education Scheme have impacted on students, lightning speed technological innovation has changed and will continue to change university culture. Having to be in paid employment to be able to afford to be a student, and having to be technologically savvy, are becoming the new norms. The latter is perhaps generic of an era, affecting far more than university life, but the former is particularised and compounded by a (dominantly) Monday through Friday, nine to five administration of services. Both issues are important to monitor.

This study seeks to add to a growing body of research into the new millennium student, who is typically enrolled full time, working up to 20 hours per week and spending less than five hours per week on campus other than for course requirements. One student's comment captured from the qualitative section of the survey questionnaire speaks for many, and the dilemma he or she expressed needs to be heard:

[I] feel as though they think I'm just lazy for missing classes, but I feel like if I don't take work when it's offered or turn work down too many times I might lose my job (or both) or get a bad work reputation and I won't be able to use them as a reference later. 
As universities seek better systems and protocols to cater for the changing needs of their consumers, and as students find themselves in a "Catch 22 " of working to study and of studying to work, constructive feedback through research is imperative.

\section{Literature review}

The surveys conducted by McGinnis, James and Hartley (2000), tracing Trends in the First Year Experience in Australian Universities in 1994 and again in 1999 (with additional items relating to learning technologies), provide a highly compatible foundation for the present investigation, yet another five years on, albeit a much smaller sample $(n=148)$ at just one campus not seven. Nevertheless, the questions of those much larger surveys $(n=4,028$ in 1994 and $n=2,609$ in 1999) were influential in the formulation of the present survey to compare findings, notably that the most significant difference between the transpiring five years was not only the increase in the proportion of full time students engaged in paid work (from $42 \%$ in 1994 to $51 \%$ in 1999 , a 9\% increase) but also in the average of employed hours (from 11.04 hours per week in 1994 to 12.59 hours in 1999, a 14\% increase). From the LSAY30 report for the year 2000 (Vickers, Lamb \& Hinkley, $2003{ }^{1}$ ), almost half of the young students surveyed worked between 6 and 20 hours per week, and a further $11 \%$ were employed more than 20 hours per week. The researchers call for a closer investigation of the trend of less attachment to university life as paid work competes for campus time outside of class contact hours. This current study seeks a ratification of those findings by asking similar questions, especially of students in a regional campus with a high level of low socio-economic status students ${ }^{2}$, to explore the impact of paid employment in the areas of service delivery, along with access and competent use of technologies.

One measure of impact is the rate of dropping out, reasons for which are not isolated to paid employment but nevertheless are influential. AbbottChapman $\left(1999^{3}\right)$ reports, for instance, that, at the University of Tasmania in $1997-8,39.2 \%$ of first year students said they had been inadequately equipped for the demands of university life and, as many reports attest, the first year is the most vulnerable to dropping out. The 1999 national attrition rate of commencing undergraduate students (DEST, 2000) was 22\%, with James Cook University almost the highest at 33\% ${ }^{4}$. LSAY30 (Vickers, Lamb \& Hinkley, 2003) found that the drop out rate of those enrolled full time, working between 21-29 hours per week, was $16 \%$ and, of those working more than 30 hours per week, attrition was $17 \%$. The drop out rate for those working less than 20 hours of paid work per week, however, is barely more than for those not working at all although, as Alderton and Muller (2000, p.39) report, "full time students working part time experienced greater levels of strain symptoms than full time workers 
studying part time." The Promnitz and Germain survey conducted at James Cook University, Townsville Campus, in 1996 finds considerable support for the negative impact of employment on the decision to leave or to defer, so much so that a key recommendation of the report is for core subjects to be timetabled late in the day or in the evening on alternate years. Vickers, Lamb and Hinkley (2003, p.18) concur, that "universities are being forced to reconsider how they deliver their educational programs and services as they realise that many full time students are also becoming full time workers." If balancing employment and study is a precarious process (Promnitz \& Germain, 1996), the add on burdens of family responsibilities, limitations of service delivery and inadequate technological expertise further reduce the tenability of degree completion.

Lim and Lee's (2000) study of IT skills of 80 undergraduate students at Deakin University, Geelong Campus (which the researchers claim was the only study investigating the IT skill level of undergraduates of its kind at that time ${ }^{5}$ ), locates a public assumption that all school leavers should be, or in the near future will be, computer literate, an assumption also adopted by teaching staff. This implication is alarming when, of the $87 \%$ who said they knew how to use the Web, $21 \%$ did not know how to use Web addresses (URLs), a further $9 \%$ had never heard of URLs, 30\% did not know how to download files from the Web and a giant $64 \%$ did not know how to read PDF files. As the writers recommend (Lim \& Lee 2000, p.6), "given the increasing use of Web based teaching resources... there is an urgent need for IT training on the use of the Web for university students." The present study benefits from having asked similar questions to flush out any lingering currency of assumptions which Lim and Lee (2000) uncovered, assumptions which tend to underwrite a number of otherwise valuable studies (Oliver \& Omari, 1999; Choy, McNickle \& Clayton, 2001). Indeed, in the Choy, McNickle and Clayton (2001, p.11) study of online learners $(n=201)$, interviewees who presumably were technologically competent 'shared a common view that many teachers and tutors are not adequately trained for online delivery', a complication which was not able to be considered in the JCU study.

Not only technological savvy is important, however. Access to resources computers, Internet, software, databases - plays a critical role. In 1999, Buchsbaum assessed that half the American student population was without a computer and thus disadvantaged. Currently that proportion may be considerably smaller, which this present study has some capacity to determine. That students do not follow set study times and can study in multiple locations lead Buchsbaum (1999, p.20) to recommend that all students should have their own notebook PCs because, as he states, "computer labs are not the answer... their inherent limitations make them ill-equipped to meet students' growing technology demands." As the Vice 
President of Education for the Dell Group, Buchsbaum's advocacy for putting laptops into the hands of each student may be prejudiced, yet he rightly recognises, as do other researchers cited in this literature review, that the metamorphosis of the tertiary student requires an equally robust degree of fit in the metamorphosis of access to and competent use of technologies to cater for changing needs of a new generation of students.

Another impact area on students in paid employment, more so than those students who are not obliged to work, is the scheduling of lectures, tutorials and workshops, as well as the time spent on campus connecting with other students in both formal and informal groupings. As Vickers, Lamb and Hinkley (2003, p.vi) observe, "the more hours per week that a student spends in classes, laboratories, and practical training, the less likely the student is to drop out." But as other commitments detract from working students' availability, time other than for the very basic requirements of course curricula is spent off campus rather than on, a relatively new dynamic in scholarship, a dynamic which can be compensated for - and further influenced by - technology:

The impact of 'adding on' and 'speeding up' is very much in evidence on university campuses. More faculty are experimenting with multimedia presentations or delivering their courses over the Internet and more fulltime students are taking at least some of their academic programme at a distance (to get more course choice or to juggle work, family and study schedules). (Paul, 2000, p.40)

That more and more students are in paid employment is, according to Abbott-Chapman (1999), a "national phenomenon" requiring sharp attention to alternative delivery modes, flexibility and astute use of technologies to compensate for a major trend shift in a relatively short time span, a trend which the McInnis, James and Hartley (2000) study tracks as noticeable in just five years, between 1994 and 1999. A further five years on, observations in similar vein to assess the fit of work with study, study with technology, and technology with the academy are wise in an era of volatile change.

\section{Methodology}

The pivotal components for this endeavour were the development of the survey questionnaire, its pathway through ethics committee approval, its implementation as interviews and, finally, entry of data from the questionnaires into Statistical Package for the Social Sciences (SPSS) Version 12 for analysis. The complication in the development of the questionnaire that offered some consternation was whether or not childcare was a form of employment. This helped clarify the title of the project and the word 'paid' was introduced. That the survey needed to cater for the self employed led 
to modification of variables: casual or set hours, on call, part time, full time, self employed was changed to flexible, set, on call categories. A consideration was for interviewers to note the time of participants' responses. About $20 \%$ of lectures and tutorials are held after $5 \mathrm{pm}$ and, to achieve the best representative sample, $20 \%$ of interviews also needed to be with those attending after $5 \mathrm{pm}$. A schedule was drawn so that each of the eight interviewers had an opportunity to include such representation. The time of interview became a field in the data base.

It was important that interviews were conducted face to face, rather than use technology to gauge adoption of and competency in technological processes. Thus email responses, albeit with the potential of a higher response rate, were not considered appropriate. Interviewers physically approached a random selection of volunteer participants at a spread of locations around campus, asking three screening questions for candidature as a participant before commencing the 20 minute interview:

1. Are you over 18 years old?

2. Are you a student of James Cook University, Cairns Campus?

3. Are you or have you been in paid employment during the last two weeks?

Over 10 days in May 2005, 148 face to face interviews were conducted on JCU Cairns Campus, $80.4 \%$ before 5 pm, $19.6 \%$ after 5 pm.

The missing piece in this research was the percentage of students in paid employment at JCU Cairns Campus. The University has been unable to supply its own figures of those in full or part time work, probably because this is the province of surveys rather than enrolment data. Because the survey screened for those in work up to two weeks prior to the interviews, those not in work were not represented in this survey, which would have been useful for comparison.

\section{Student profiling}

Of the 2,625 undergraduate students (including Honours enrolments, census May 2005) at James Cook University Cairns Campus, the $5.6 \%(\mathrm{n}=$ 148) sample of this study is in close alignment with the whole undergraduate student body (Table 1) which suggests extrapolation potential for all working students.

In an overview before discussing data analysis in more detail, $70.9 \%$ of the sample worked up to 20 hours per week and $14.2 \%$ were in more than 30 hours of paid work per week, with both sexes averaging close to 18 hours' employment per week. 38 or $26 \%$ had more than one job in the two weeks 
leading up to the survey and 36 or $24.3 \%$ had the additional responsibility of primary childcare ( $72 \%$ female, $28 \%$ male). Those in their first year of study comprised $32 \%$.

Table 1: Comparison of sample student profile with campus wide student profile (\%)

\begin{tabular}{|c|c|c|c|c|c|}
\hline & Female & Male & Full time & Part time & First year \\
\hline Sample \% & 68.2 & 31.8 & 70.9 & 29.1 & 32.0 \\
\hline Campus \% & $64.0^{*}$ & 36.0 & $69.0^{*}$ & $31.0^{*}$ & $30.0^{* *}$ \\
\hline
\end{tabular}

* 2000 DETYA Trends in the First Year Experience, Cairns and Townsville Campuses ** May 2005 James Cook University Cairns Campus statistics

The following covers salient data and discussion about students in paid employment, their attitudes to service delivery, their skills abilities with the technological requirements of being a student, and their attitudes toward the web based technologies adopted by James Cook University.

\section{Findings}

Needing to work is no whimsy for $95.4 \%$ of this sample of students in paid employment, who assessed their income as important to their financial viability in remaining enrolled. Only $26 \%$ worked in fields aligned to their courses of study, leaving $74 \%$ employed in unrelated areas, an indication that a job, any job, is needed to pay the bills. The spike of $38 \%$ in the "more than I'd like it to" category of the felt impact of work on study indicates a discomfort in the juggle of commitments, a lack of fit in the balance between work and study, especially obvious when added to the categories "sometimes" and "very much." In total, 78\% reported that work impacted detrimentally upon study. De la Harpe, Radloff and Parker (1997) identify a gritty lack of fit between what students are saying and what academics expect: "academics may lament this trend and long for the days when full time students were really full time, [but] the realities of today's university classrooms are very different." The reality is that up to $51 \%$ of first year, full time undergraduate students undertake some form of work (McInnis, James \& Hartley, 2000), although much of this is part time and less than the dangerous threshold of 20 hours per week. Yet another point to ponder from this current study is that those enrolled part time reported working has a higher intrusion factor $(81.4 \%)$ than full time students $(75.2 \%)$, which is the reverse of Alderton and Muller's (2000) finding.

Undertaking more than 20 hours per week paid work and being enrolled full time makes students up to $160 \%$ more likely to drop out (Vickers, Lamb \& Hinkley, 2003). With $29 \%$ of this research sample working more than 20 hours per week, men $6 \%$ more so than women, with the potential 
attrition of this sample of working students, self declared as $25 \%$, and a commencing undergraduate attrition rate at JCU (both Cairns and Townsville campuses) of 33\% (McInnis, James \& Hartley, 2000), it is not a giant leap to make associations and name this as a very vulnerable group indeed. With a potential of extrapolation to the Cairns Campus working student community, the research findings from this group are indeed valuable.

The finding, for instance, that, overall, 32.4\% would be, or has been, prepared to skip classes in favour of work, more specifically $31.1 \%$ for a lecture, $23.6 \%$ for a tutorial, is valuable as a matter for concern. Apart from other more obvious reasons - family commitments and sickness - the responses of tiredness for missing a lecture at $39.9 \%$ and a tutorial at $23 \%$ are also concerning. It would have been useful to measure the tiredness factor for those not in some form of paid employment - perhaps tiredness just goes with the territory of being a student - but it is fair to assess this group as weary. Paul's (2000, p.39) suggestion links in here:

\footnotetext{
[t]here is no logical reason why increasingly effective technologies cannot be employed to take much of the passivity out of teaching and learning, and free up the professor for intensive, well-informed and ultimately very efficient use of his or her time in customised one-to-one or small group sessions with well-prepared students. This is obviously a much better model than students sleeping through a droned lecture or faculty having to teach to the lowest common denominator in the classroom at the expense of learning opportunities for the more capable students.
}

Indeed, lectures appeared less imperative than tutorials. On average, $22.8 \%$ would not attend a lecture on occasions and $19.8 \%$ would fail to participate in a tutorial (for any one or a composite of reasons). Attendance attitudes to lectures, tutorials and workshops led into an exploration of multiple choice, desirable alternatives or complements to existing scheduling (Table 2).

During the responses to the multiple choice question - "Which of the following would enhance your ability to study at university?" interviewers reported in debrief that this section produced a ponderous consideration from survey participants, more so than any other of the 37 questions. Consistently, women sought more choice in delivery (except, interestingly, video conferencing $26.7 \%$ compared with male interest of $31.2 \%)$. Online course delivery appealed most for both men $(38.3 \%)$ and women $(42.6 \%)$. The least popular for both sexes was weekend delivery of classes but week night delivery (Monday-Friday, 5-9pm) and limited attendance (seminars, block lectures) were equally popular alternatives or supplements (32.4\%). Intensive courses sandwiched between the two major terms were also highly favoured (39.6\% for women, $23.4 \%$ for men). Course 
specific chat rooms attracted favour as the second highest interest area (35.8\% total).

Table 2: Multiple choice: Interest in alternative modes of delivery ( $\mathrm{n}$ and \%)

\begin{tabular}{|l|c|c|c|c|c|c|}
\hline \multirow{2}{*}{\multicolumn{1}{|c|}{ Alternative mode }} & \multicolumn{2}{c|}{ Female } & \multicolumn{2}{c|}{ Male } & \multicolumn{2}{c|}{ Total } \\
\cline { 2 - 7 } & $\mathrm{n}$ & $\%$ & $\mathrm{n}$ & $\%$ & $\mathrm{n}$ & $\%$ \\
\hline Intensives in term breaks & 40 & 39.6 & 11 & 23.4 & 51 & 34.5 \\
\hline $\begin{array}{l}\text { Limited attendance seminars, or } \\
\text { block lectures }\end{array}$ & 35 & 34.7 & 13 & 27.7 & 48 & 32.4 \\
\hline Online courses & 43 & 42.6 & 18 & 38.3 & 61 & 41.2 \\
\hline DVD/ video conferencing & 27 & 26.7 & 15 & 31.2 & 42 & 28.4 \\
\hline Weekend lectures & 19 & 18.8 & 7 & 14.9 & 26 & 17.6 \\
\hline Week night classes 5-9pm & 36 & 35.6 & 12 & 25.5 & 48 & 32.4 \\
\hline $\begin{array}{l}\text { Chat room or subject specific } \\
\text { online medium }\end{array}$ & 35 & 34.7 & 18 & 38.3 & 53 & 35.8 \\
\hline
\end{tabular}

The expression of positive anticipation of change from the more traditional lecture/tutorial combination offers much potential for further investigation. As Paul (2000, p.39) recommends, "the application of new technology to university teaching and learning is more than just a new way to do old things. Whether by accident or design, it is changing the culture of our institutions and challenging the traditional authority of the professor." Ziman (2003), for instance, reports on the measurable improvement of grades when what had previously been a traditional lecture and tutorial based second year subject in Edith Cowan University's Human Biology degree was reshaped into student led mini-conferences. Not only were students' results improved but also this flexible teaching project was more enthusiastically received than conventional delivery by students striving towards more active participation (Oliver \& Omari, 1999).

The lack of active participation outside of course requirements of the new millennium, working student, however, is a different concern, if the role of informal, extra-curricula learning groups can be cited as an important component to the well-rounding of scholastic experience. From within this group under investigation, 82 respondents $(55.4 \%)$ spend less than 5 hours per week on campus other than for course requirements. According to Paul (2000, p.43), the "informal, social role of a university is central to its authority and effectiveness and it explains much of the staying power of prestigious universities in particular. Any strategy for change will ignore this at its peril." Course specific chat rooms, supported by $36 \%$ of respondents, may be the compromise. As working students rush from commitment to commitment, this technological medium may offer a replacement or supplement to retain or attain connectedness bemoaned as missing from contemporary scholarship, although to date, even though discussion boards are built increasingly into undergraduate course structuring, acceptance of subject specific chat rooms is not supported by 
research (Dixon \& Pelliccione, 2004). Many would be participants lack the confidence to participate, fearful of making mistakes in a visible medium, of experiencing technical problems, and of appearing foolish. That over one-third of respondents in this study claimed interest, however, needs nurturing because this cohort of students is already, dominantly, online.

The dominant place for accessing a computer was the home $(80.4 \%$, either exclusive use or satisfactory share use), although the computer facilities on campus were also highly accessed (77.7\%). A comparison between the combination of home use of a computer $(80.4 \%) /$ home use of Internet $(74.3 \%)$ and computer use at JCU $(77.7 \%) /$ access to Internet $(65.5 \%)$ may be a story about broadband, better range of software on campus and making use of time between class commitments. While $31.3 \%$ owned a laptop (a considerable shortfall on Buchsbaum's 1999 advocacy that laptops should be put into the hands of each student) and $27 \%$ access computer, Internet and printing facilities at their place of work, just $12.2 \%$ acknowledged using the Internet at their place of work, which may indicate that printing or typing up study assignments at work is more pertinent than web usage. The small percentage $(3.4 \%)$ accessing online facilities at an Internet café may be to do with distance from this regional campus and lack of online facilities at home. Access and competency, however, are two separate issues.

Two questions were posed for competency self assessment, the first descriptive and the second a Likert scale of low through to high level of technological skills (cross-tabulated in Table 3). In the descriptive approach, $75.7 \%$ claimed reasonable to high level competency, whereas $88.5 \%$ self assessed as medium to high on the Likert scale, an observable difference between the two styles of response which the two questions sought to capture. The picture from the survey is that about one quarter of students (descriptor capture) is just coping with the technological requirements of being a university student and a further one third is ambivalent (Likert scale capture). That this survey was conducted in week 9 of a 13-week semester needs noting. Dixon and Pelliccione (2004, p.2) relay the assessment that "learners in higher education settings perceived the Internet as an appropriate delivery medium but warned that frustration with technical aspects could lower student satisfaction and ultimate achievement of learning outcomes."

Dixon and Pelliccione (2004) grasp the essence of what is at stake:

While it is increasingly important for universities to implement a growing array of online courses in order to remain economically competitive, questions remain regarding pedagogical issues, economic costs, philosophical issues, policy issues and personal issues such as student preference for online versus face to face delivery. 
Table 3: Descriptive and Likert scale cross tabulation: Self assessment of technological competency

\begin{tabular}{|l|c|c|c|c|c|c|}
\hline \multicolumn{1}{|c|}{ Descriptors } & $\begin{array}{c}\text { Very } \\
\text { low }\end{array}$ & Low & $\begin{array}{c}\text { Med- } \\
\text { ium }\end{array}$ & High & $\begin{array}{c}\text { Very } \\
\text { high }\end{array}$ & Total \\
\hline I'm completely hopeless & 2 & 2 & 0 & 0 & 0 & 4 \\
\hline I struggle most of the time & 1 & 6 & 0 & 0 & 0 & 7 \\
\hline $\begin{array}{l}\text { I manage but wish I was more } \\
\text { able }\end{array}$ & 0 & 6 & 17 & 2 & 0 & 25 \\
\hline $\begin{array}{l}\text { I manage and I know how to ask } \\
\text { for help }\end{array}$ & 0 & 0 & 17 & 8 & 0 & 25 \\
\hline $\begin{array}{l}\text { I'm usually okay but have } \\
\text { occasional problems }\end{array}$ & 0 & 0 & 20 & 23 & 2 & 45 \\
\hline I'm very confident and able & 0 & 0 & 2 & 15 & 25 & 42 \\
\hline Total & 3 & 14 & 56 & 48 & 27 & 148 \\
\hline
\end{tabular}

With $24.8 \%$ anticipating the trend toward universities becoming more online negatively, and $36.1 \%$ reserving their opinion by remaining neutral, a decidedly low lack of fit is apparent here, although $39.1 \%$ felt positive about the future marriage of university life and technology.

Table 4: Feelings about universities adopting more and more web based technologies by age ( $\mathrm{n}$ and \%)

\begin{tabular}{|c|c|c|c|c|c|c|c|}
\hline \multicolumn{2}{|c|}{$\begin{array}{c}\text { Age of participant } \\
\text { (yrs) }\end{array}$} & $\begin{array}{c}\text { Very } \\
\text { negative }\end{array}$ & Negative & Neutral & Positive & $\begin{array}{c}\text { Very } \\
\text { positive }\end{array}$ & $\begin{array}{c}\mathrm{n}=\text { total } \\
\%=100\end{array}$ \\
\hline \multirow{2}{*}{$18-20$} & $\mathrm{n}$ & 0 & 8 & 13 & 14 & 5 & 40 \\
\cline { 2 - 8 } & $\%$ & 0.0 & 20.0 & 32.5 & 35.0 & 12.5 & 100.0 \\
\hline \multirow{2}{*}{$21-25$} & $\mathrm{n}$ & 4 & 6 & 15 & 13 & 3 & 41 \\
\cline { 2 - 8 } & $\%$ & 9.7 & 14.6 & 36.6 & 31.8 & 7.3 & 100.0 \\
\hline \multirow{2}{*}{$26-30$} & $\mathrm{n}$ & 1 & 4 & 7 & 4 & 1 & 17 \\
\cline { 2 - 8 } & $\%$ & 5.9 & 23.5 & 41.2 & 23.5 & 5.9 & 100.0 \\
\hline \multirow{2}{*}{$31-35$} & $\mathrm{n}$ & 0 & 2 & 2 & 4 & 1 & 9 \\
\cline { 2 - 8 } & $\%$ & 0.0 & 22.2 & 22.2 & 44.5 & 11.1 & 100.0 \\
\hline \multirow{2}{*}{$36-40$} & $\mathrm{n}$ & 1 & 3 & 9 & 1 & 2 & 16 \\
\cline { 2 - 8 } & $\%$ & 6.2 & 18.8 & 56.3 & 6.2 & 12.5 & 100.0 \\
\hline \multirow{2}{*}{$40+$} & $\mathrm{n}$ & 4 & 3 & 7 & 7 & 4 & 25 \\
\cline { 2 - 8 } & $\%$ & 16.0 & 12.0 & 28.0 & 28.0 & 16.0 & 100.0 \\
\hline total & $\mathbf{n}$ & $\mathbf{1 0}$ & $\mathbf{2 6}$ & $\mathbf{5 3}$ & $\mathbf{4 3}$ & $\mathbf{1 6}$ & $\mathbf{1 4 8}$ \\
\hline mean & $\mathbf{\%}$ & $\mathbf{6 . 3}$ & $\mathbf{1 8 . 5}$ & $\mathbf{3 6 . 1}$ & $\mathbf{2 8 . 2}$ & $\mathbf{1 0 . 9}$ & $\mathbf{1 0 0 . 0}$ \\
\hline
\end{tabular}

In a cross tabulation of age group with feelings about universities adopting more and more web based technology (Table 4), the age group with the most trepidation was the 36-40 year olds, with a combined "positive" to "very positive" response of just $18.7 \%$. The most positive groups were 18 $20 \mathrm{~s}(47.5 \%), 31-35 \mathrm{~s}(55.6 \%)$ and over $40 \mathrm{~s}(54 \%)$. The question was not defined but seemed to be readily perceived. The neutral response $(36.1 \%)$ may have indicated a lack of strong opinion either way, or a capitulation to 
the inevitable. The response may also mean that the question was illdefined enough to result in such high ambivalence. Again from Paul (2000, p.34-5),

[t]o change a technology is to change the culture of an organisation, whether or not this is planned or recognised. It follows that university leaders need to pay a lot more attention to the potential impact of new technology, both positive and negative, and attempt to plan for rather than merely cope with change as it happens.

An indicator of the slippage from planning to coping - the degree of fit appeared with the acid-test question of level of satisfaction, a categorical "yes" or "no" whether the university caters well for students in paid employment. This final check and balance question flushed out $40 \%$ who said "no." Evans' view (2000, p.223) can be used in summary:

\footnotetext{
to be flexible requires explicitly understanding learners' needs, interests and contexts and then responding appropriately at the policy, administration and teaching levels. Whether in the world of work or education, the costs of ignoring or avoiding such an understanding are likely to be serious, either in terms of profitability or educational effectiveness.
}

To flow on from Evans, both profitability and educational effectiveness will suffer unless JCU addresses this lack of fit expressed by $40 \%$ of this sample, poised as it is to extrapolate to the whole of campus population of undergraduates in paid employment. The preferences of this working group of students were not only for a more diverse range of learning modes but also for alternative times for lectures and more flexible times for tutorials (without the tag of "mandatory attendance"), consistency in expectations and treatment across disciplines, and a higher level of acceptance of the difficulties of managing work commitments and study. The advance availability of readings via the university bookshop before semester commencement would also be deemed helpful. The conclusions here are serious, that the university needs more effective means and media to cater for the needs of a growing number of students, both part time and full time, in paid employment.

\section{Summary}

This survey conducted in May 2005 with 148 students in paid work at James Cook University, Cairns Campus, sought to determine students' ease and proficiency in accessing web based technology, and their experiences of service delivery. Considering that the typical university student is enrolled full time and works 18 hours per week, it may not be surprising that $78 \%$ of those surveyed reported that work impacted study detrimentally. Surprising, however, is the discovery that a quarter of this 
random sample said they were barely coping with the technological requirements of being a university student at the 9 week mark of a 13-week semester. A similar $24.8 \%$ viewed the trend for universities to deliver more of their services online negatively with $36.1 \%$ reserving their opinion by remaining neutral. Although $39.1 \%$ felt positive about the future consolidation of university life with technology, such mixed opinion deserves attention. What universities expect of or even assume about the technological capabilities and resources of their students for any university, not only JCU, may be "out of sync" with the grass roots level of praxis. The acid test question - a categorical "yes" or "no" whether the university caters well for students in paid employment - flushed out $40 \%$ who said "no", which does point in that direction. Both profitability and educational effectiveness will suffer unless JCU addresses this lack of fit expressed by $40 \%$ of this sample, poised as it is to extrapolate to the whole of campus population of undergraduates in paid employment who work to study and/or study to work in their field of choice. The high level of positive anticipation of change away from the more traditional lecture/tutorial combination along with over one-third of respondents claiming interest in subject specific chat environments, however, offers potential to enhance levels of satisfaction with service delivery. This, in turn, may help to offset the trend of less attachment to university life as paid work competes for campus time outside of class contact hours.

\section{Recommendations}

Although the findings of this particular survey are specific to James Cook University, Cairns Campus, any or even every university campus would be well-advised to conduct a skills and resource audit of first year students (at the very least) if they have not already. A bottom up inquiry rather than a set of top down assumptions about technological competencies is recommended, not just for those in paid employment. Other recommendations emerge from this study, neither generalisable to all faculties of JCU nor necessarily to other university campuses:

1. Offer more choice in timetabling and modes of delivery. This is a strong need from this sample of students.

2. Make a whole of campus policy that those in paid employment and those with primary child care responsibilities have first choice of tutorial placements or other selective processes.

3. Remove the word "mandatory" or words to similar effect from all attendance literature.

4. Alternatively deliver (at least) first year lectures, one year daytime, one year early evening.

5. Abolish deadlines on Fridays as a whole of campus policy. Most working people need a weekend to meet a deadline. 
6. Encourage more academic staff to accept email submissions of assignments using the 'SafeAssignment' portal to save extra journeys to campus for such purpose.

7. Advance the ordering and stocking of set texts by up to four weeks to enable earlier availability of readings via the university bookshop.

8. Investigate more thoroughly the use of and level of participation in subject specific chat room or discussion board tutorials.

9. Set aside a period before the commencement of each major semester for classes in the use of systems and software. Call it T-Week, Technology Week, when intending scholars undertake crash week-long courses rather than sandwiching hour-long micro lessons into valuable term time.

10. Have structured, points earning sandwich courses eg. University Technology I.

11. Consider making technological competency a prerequisite for university entry. .

12. For those students technologically challenged (no typing skills, technoshy, physically limited, blind) recruit techno-buddies who are prepared to assist new students

13. Have a techno-busters hotline, especially for after hours' assistance. Third year students in certain technologically oriented courses could offer this in exchange for points towards a subject.

14. Make James Cook University, Cairns Campus, "Worker friendly" at a policy level, not unlike the positioning of some workplaces as "Children friendly."

\section{Acknowledgements}

Members of the group developing the survey direction and designing the key instrument conducted 148 interviews at James Cook Uuniversity, Cairns Campus, March-May 2005 and are acknowledged for their contributions: Tara Dallapozza, Tomomi Haneda, Jennifer Hoffman, Roger Jobling, Mariko Molleneaux, Alisa Patterson, Judy Scantlebury. The application for approval of the questionnaire by the Ethics Committee was guided by Dr James Coughlan.

\section{References}

Abbott-Chapman, J. (1999). Changing students, changing needs. Australian College of Educators, Tasmanian Chapter. [viewed 18 Mar 2005, verified 3 Mar 2006]

http:/ / www.austcolled.com.au/index.php?option=com_content\&task=view\& $\mathrm{id}=2262 \&$ Itemid $=613$

Alderton, S. \& Muller, J. (2000). Working, studying and parenting: Multiple roles and role strain. Australian Journal of Career Development, 9(2), 38-43. 
Buchsbaum, T. (1999). Campus-wide computing initiatives (technology information). T H E JOURNAL (Technological Horizons in Education), 26, 20-27. [viewed 21 Mar 2005] http:/ / www.thejournal.com/magazine/vault/A2076.cfm

Choy, S., McNickle, C. \& Clayton, B. (2001). Online support for VET clients: expectations and experiences. [viewed 22 Feb 2006] http://www.avetra.org.au/abstracts_and_papers_2001/Choy-McNickle.pdf

de la Harpe, B., Radloff, A. \& Parker, L.(1997). Time spent working and studying in the first year: what do students tell us? Teaching and Learning Forum '97. Curtin University of Technology. http://lsn.curtin.edu.au/tlf/tlf1997/delaharpe.html [viewed 14 May 2005].

DEST (Department of Education, Science and Training) (2000). Characteristics and performance indicators of Australian higher education institutions. Occasional Paper Series 01-B, Higher Education Division, Canberra. [verified 3 Mar 2006] http://www.dest.gov.au/sectors/higher_education/publications_resources/profiles/ archives/indicators_of_australian_higher_education_institutions.htm

DEST (Department of Education, Science and Training) (2002). Higher education at the crossroads: An overview paper. Ministerial discussion paper, Canberra. [verified 3 Mar 2006] http:/ / www.backingaustraliasfuture.gov.au/publications/ crossroads/default.htm

DETYA (Department of Education, Training and Youth Affairs) (2001). The effectiveness of models of flexible provision of higher education. Evaluations and Investigations Programme, Higher Education Division, Canberra, Australia. [verified 3 Mar 2006] http://www.dest.gov.au/archive/highered/eippubs/eip01_9/default.htm

Dixon, K. \& Pelliccione, L. (2004). Reactions to online learning from novice students in two distinct programs. In R. Atkinson, C. McBeath, D. Jonas-Dwyer \& R. Phillips (Eds), Beyond the comfort zone: Proceedings of the 21st ASCILITE Conference (pp. 255-262). Perth, 5-8 December. http://www.ascilite.org.au/conferences/perth04/procs/dixon.html

Evans, T. (2000). Flexible delivery and flexible learning: Developing flexible learners? In V. Jakupec \& J. Garrick (Eds), Flexible learning, human resource and organisational development: Putting theory to work. (pp. 211-224). London: Routledge.

Lim, K.F. \& Lee, J. (2000). IT skills of university undergraduate students enrolled in a first-year unit. Australian Journal of Educational Technology, 16(3), 215-238 http://www.ascilite.org.au/ajet/ajet16/lim.html

McInnes, C., James, R. \& Hartley, R. (2000). Trends in the first year experience in Australian universities. Department of Education, Training and Youth Affairs, Commonwealth of Australia, Canberra. [verified 3 Mar 2006] http:/ / www.dest.gov.au/archive/highered/eippubs/eip00_6/fye.pdf

Oliver, R. \& Omari, A. (1999). Using online technologies to support problem based learning: Learners' responses and perceptions. Australian Journal of Educational Technology, 15(1), 58-79. [viewed 22 Feb 2006] http://www.ascilite.org.au/ajet/ajet15/oliver.html 
Paul, R. (2000). Digital technology and university sovereignty: Compatibility or collision course? In V. Jakupec \& J. Garrick (Eds), Flexible learning, human resource and organisational development: putting theory to work. (pp. 30-46). London: Routledge.

Promnitz, J.\& Germain, C. (1996). Student support services and academic outcomes: Achieving positive outcomes. Evaluations and Investigations Program, Department of Employment, Education, Training and Youth Affairs. [viewed 14 Mar 2005] http:/ /www.dest.gov.au/archive/highered/eippubs/eip00_6/fye.pdf

Vickers, N., Lamb, S. \& Hinkley, J. (2003). Student workers in high school and beyond: The effects of part-time employment on participation in education, training and work. (Longitudinal surveys of Australian youth Research Report No 30). Australian Council for Educational Research, Canberra. [viewed 14 Mar 2005, verified 3 Mar 2006] http:/ / www.acer.edu.au/research/projects/lsay/reports/lsay30.pdf

Ziman, M. (2003). In-class pharmacology conference: Student communication and flexible delivery in an authentic learning experience. Uniserve Science Improving Learning Outcomes Symposium Proceedings. [viewed 14 May 2005, verified 3 Mar 2006] http://science.uniserve.edu.au/pubs/procs/wshop8/outws003.pdf

\section{Endnotes}

${ }^{1}$ LSAY is a program of longitudinal surveys of young people managed by the Department of Education, Science and Training (DEST) and the Australian Council for Educational Research (ACER), conducted annually since 1995, examining (among other things) tertiary students' participation in paid work. The sample size in 1999 was 8,735 and in 2000 was 7,889 .

${ }^{2} 24.1 \%$ as share of all JCU domestic students, 2000 cf national average of $14.8 \%$ (DEST 2000).

${ }^{3}$ This research was conducted late 1997 and early 1998 using a post out, whole of campus questionnaire survey. The $34 \%$ response rate $(n=3650)$ was found to be representative of the total student population.

${ }^{4}$ The University of Sunshine Coast at $37 \%$ is the highest but it is also one of the newer campuses in Australia (established 1996) which may have some bearing. The other equally high attrition rate $(33 \%)$ comes from the University of Notre Dame but, with only 220 students, the comparison is unwarranted. The remaining 35 universities are below $30 \%$.

${ }^{5}$ This sample is made up of $70 \%$ first year students direct from high school, $7 \%$ mature age students and $23 \%$ students with prior university experience.

Marilyn J. Anderson BA Hons, BSoc.Sci, c/- Dr James Coughlan, Department of Anthropology, Archaeology and Sociology, James Cook University, Cairns Campus, Smithfield Qld 4879, Australia.

Email: marilyn.anderson@jcu.edu.au 